\title{
A Procedure for Selecting Naturalistic Images Based on Appleton's Theory
}

\author{
Sara Farbod
}

\begin{abstract}
Many scholars have highlighted the relationship between Appleton's theory and safety perception in several environments. However there is no research which applies this theory to naturalistic context. In addition there is no study to introduce a procedure to select environmental stimuli which represent naturalistic landscapes and operationalize Appleton's theory simultaneously. The present paper proposes a sequential method of design which uses Appleton's prospect- refuge theory to select such stimuli. The validity of the method is discussed.
\end{abstract}

Index Terms-Environmental stimuli, naturalistic landscapes, prospect-refuge theory, sequential method.

\section{INTRODUCTION}

Urban biological diversity has immense economic, aesthetic, and ethical values [1]. Nevertheless, in recent decades, the growth of human population and urbanization have led to a huge losses of urban biodiversity through ecosystem deterioration and reduction of green spaces [2]. Urban green spaces have significant conservation values because they could be remnant habitats of rare and endangered species with a high level of bio diversity, which can contribute to ecosystem development and benefit urban population [2].

Realizing the importance of urban biodiversity has prompted landscape architects to put forward plans for creating more ecologically friendly urban landscapes "to preserve nature, keep disturbance to nature at a minimum and to restore, create or emulate nature where it does not exist" [3]. In this naturalistic style of landscape design, conventional artificial features are limited.

Safety, whether perceived or real, is one of the key elements in the design of urban environments [4]. Although, naturalistic landscapes can provide benefits for people, but the perceived threats in naturalistic urban landscapes is far greater as compared to formal, and well-manicured urban landscapes [5]. This threat appears to be from nature, other humans, accidents, or the subconscious mind. In a study by Jorgensen, Hitchmough, and Dunnett [6], naturalistic woodlands were considered to be unsafe because of perceived fears of assault, theft, harassment, and threats from groups of youngsters. This is confirmed by other studies [7]-[10].

Some scholars [11]-[13] also found that increasing naturalistic dense vegetation decreases the sense of safety in urban areas. Parks with dense, unmaintained vegetation

Manuscript received April 15, 2014; revised June 17, 2014.

Sara Farbod is with the Islamic Azad University (Neyshabur Branch), Neyshabour, Iran (e-mail: sarafarbod1357@yahoo.cm). become a big risk to people [14] while well-maintained vegetation that clearly appears to have been "designed" enhances the security and attractiveness of urban parking lots [15].

Appleton's prospect-refuge theory utilizes an approach, which seems sensitive toward perception of personal safety for delineation of human environmental preferences [16], [17]. Prospect-refuge theory is based on the notions of habitat theory which argues that humans the same as other creatures are inclined towards environments or habitats that guarantee or increase their survival. Prospects and refuges offer the spatial and geographical mechanisms, through which mankind enhances his or her safety: locations that allow humans to watch their environment as clearly as possible and without being seen [16], [17]. As Appleton [16] argued the perception of landscape, either natural or man-made, pertains to the arrangement of things combined together to make a chance for prospect and refuge. While this basic strategic may no longer be needed in modern day, they still persist in the mind associated with aesthetic preference. Appleton [16], moreover, explained about functional descriptions of the physical or symbolic characteristics of surroundings that specify the perceived levels of prospect and refuge. "Any feature of situation which directly facilitates observation or indirectly suggests an opportunity to extend the field of vision fits into the category of a prospect. Any of which affords, or symbolically suggests an opportunity to hide or to attain shelter fits into the category of a refuge" [16]. As a matter of fact, Appleton devised a proposed typology of prospect and refuge in order to properly identify prospect and refuge opportunities through analysing the spatial characteristics of the environment [16]. Considering the previous developments of studies regarding theory of prospect and refuge, Appleton [17] mentioned that despite the difficulty in validating the theory, prospect and refuge could be useful in analysing landscapes.

Prospect and refuge theory offers a theoretical framework to understand the human ecological aspects of environmental design [18]. Loewen, Steel, and Suedfeld [19] suggested, however, that another facet of refuge should be included in Appleton's definition. They proposed a further definition of refuge which is beyond merely a physical hiding-place. This is the access to help in the form of human contact. According to them a refuge can also be a place where non-threatening individuals and anyone who may be supportive can offer refuge from a predator even if it does not actually hide the victim from the seeker's view. Thus, they proposed a definition for refuge to be "a situation representing concealment or access to help for oneself, without a hiding-place for potential predators" [19]. 
The concepts of Prospect and Refuge have been widely used in the area of perceived safety research in natural spaces and open environments as well as in indoor spaces [18]-[24]. However, the related theory is not examined in the context of man-designed naturalistic urban landscape. On the other hand, although stimuli materials are widely used in landscape perception research as well as a prior selection of landscape images, this method of selection relies on agreement of authors rather than a scientific method. Therefore the purpose of present study is to introduce a reproducible method for selecting images which are naturalistic and operationalize Appleton's theory.

\section{MATERIALS AND METHOD}

This study applied quantitative strategies which involved two phases. It was conducted in naturalistic settings of urban parks in Malaysia. The context of study was limited to urban parks. The first phase of study was the selection of urban parks' naturalistic scenes, using a process informed by theory (which will be described in part B of this section). The second phase was testing the selected images using a pre-experimental design where the photographs acted as surrogates of real landscape scenes. In this paper only the first phase of this study will be discussed.

\section{A. Operationalizing Appleton's Theory (Visual Characteristics and Their Indicators)}

In this section the operational definition of Prospect, Refuge, and Escape together with their indicators are explained. Opportunity to escape is the other concept related to visual aspects related to perceived safety that has been mentioned by previous researchers [21]. However, it has not been applied to measure the perceived safety of naturalistic landscapes.

Prospect is defined as "an unimpeded opportunity to see" [16, P. 73].Woodcock [25] classified Prospect in terms of Primary and Secondary Prospects. A Primary Prospect is defined as a "good view or vista". A Primary Prospect in the present study consisted of a breakdown into Panorama and Vista (which were mentioned as symbols of Prospect by Appleton [16]). Therefore, in this study, Prospect is measured by 3 indicators - Secondary Prospect, Panorama, and Vista. Panorama is described as "a wide view from a good vantage-point" [2] while. Vista is defined as "a view which is restricted by conspicuous bounding margins" [16]. And Secondary Prospect is defined as a view from hill or other vantage point from which one might expect to have a good view [25].

Refuge on the other hand is "an opportunity to hide" [16]. In this study the concept of Refuge was measure by 3 indicators. These are Primary Refuge, Secondary Refuge and Shadow. The first two items were mentioned in Herzog and Kutzli's study [26]. The third measure (Shadow) is inspired by Appleton [2], who stated that light can symbolize Prospect while darkness denotes Refuge. Primary Refuge or Concealment refers to the view from within a hiding place [26] while Secondary Refuge refers to the view of a hiding place from a vantage point outside it. Shadow refers to dominant shadows present in the setting [27].
Meanwhile Escape is defined as "Either an exit rout from a potential threat or a connection to others who could respond in case of an attack" [21]. This concept was measured by 3 indicators. They are Multiple Pathways, Movement Ease, and Proximity to Occupied Buildings. Multiple Pathways refers to providing the opportunity for unpredictable or changeable routes for escape. Movement Ease refers to the ease of moving through a setting [27] and Proximity to Occupied Buildings refers to being close to buildings or structures in which other people who may provide help when needed may be present.

\section{B. Stimulus Material}

This research employs photographs as surrogates of actual scenes of naturalistic landscapes. The photographs were selected from a pool of over 1000 photographs taken of landscapes in several urban parks in Kuala Lumpur, Shah Alam, and Putrajaya in Malaysia. The photographs were collected from June to August 2011. All photographs were taken from a standing position, at eye level, horizontal picture plane, and use of zooming was done to compose the scenes. All photographs have minimal or no people. All were taken in day time (between 10 am to $3 \mathrm{pm}$ ), and shot from public access (walkways).

In all over 1000 images were captured. These were then selected based on quality, fittingness into any of the 9 indicator categories. Photographs with poor quality as well as the ones which did not look naturalistic or seemed not to represent any intended indicators were removed. This resulted in the selection of 172 images.

The second stage of the image selection process involved experts examination of the 172 images. These experts consisted of landscape architecture academicians in the Faculty of Design and Architecture, Universiti Putra Malaysia. This stage ended with 63 images (seven per category) that best fit one of the 9 a priori categories. The third stage involved examination of the 63 images for best fit to a category. This resulted in the final 45 images (five per category) selected.

The selected images were color printed in $13 \mathrm{~cm} \times 18 \mathrm{~cm}$ size and mounted on $15 \mathrm{~cm} \times 20 \mathrm{~cm}$ boards. A number was then assigned to each photograph. These were shown to 7 experts. The experts were made up of landscape architecture academicians in the Faculty of Design and Architecture, Universiti Putra Malaysia.

They were asked to rate the photographs as whether they are naturalistic or not based on a 5 point Likert-like scale (1= not naturalistic at all to 5=extremely naturalistic) (please refer to Appendix1). Once this is done, the same expert panel was asked to select and place each scene in any of the 9 visual categories (Panorama, Vista, Secondary Prospect, Secondary Refuge, Primary Refuge (Concealment), Shadow, Multiple Pathways, Proximity to Occupied Buildings, and Ease of Movement). The purpose was to choose five photographs for each visual characteristic indicator in the final stage. At least seven photographs were needed to have enough options to be able to select the final photographs. At the end of this stage, seven photographs were selected for each category. The process of finding the eligible scenes is explained in the next section. 
In the next stage, five other individuals with a background in landscape architecture (Ph.D students and staff of the Faculty of Design and Architecture of Universiti Putra Malaysia) were asked to read the definition of each category carefully and rate the 7 photographs in each category according to their strength in order to represent that category. The same scale was utilized for all scenes (please refer to Appendix5). Five photographs (which obtained the highest scores for each category of visual characteristics) were chosen as the final photographs and these were later presented in a booklet to respondents. Fig. 1 shows the stages for selecting the photographs.

\section{Analysis of the Result of Experts Evaluation of Photographs}

To select the eligible scenes, several key steps were involved:

Step 1: Selecting naturalistic scenes: The mean score for the naturalistic rating of each photo was calculated (please refer to appendix3). By looking at the mean rating as well as individual scores for being naturalistic, the photographs which were rated 3 (moderately naturalistic) or lower as being naturalistic were removed. 105 photographs were selected as representative of naturalistic scenes.

Step 2: Determining the frequency of photographs for each category: The researcher provided a table in which the frequency of which each photograph was chosen for a special category was recorded (please refer to Appendix4).

Step 3: Assortment of photographs: The photographs which were selected for more than two categories were removed. This was on the basis that when a picture is selected for more than two visual characteristics, this means that it is not representative of any special visual characteristic and therefore it would confuse the observer.

Step 4: Selection result: The photographs which were assigned four times or more to a particular category were kept as representatives of that category. It should be noted that if more than seven photographs for each category remained, only the ones which had the highest naturalistic ratings were kept.

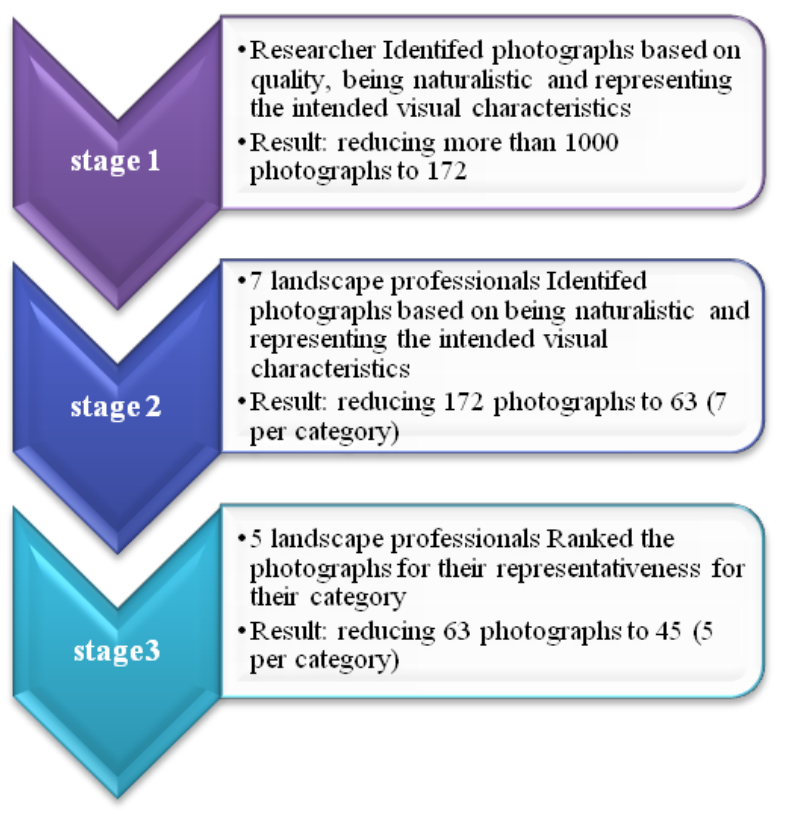

Fig. 1. Stages of photographs selection.

\section{DisCUSSION}

According to Stamps [28, P. 12] a scientific method needs "to create a well-defined concept (a definite specification), obtain a sampling frame, and obtain a random sample of the desired specifications". He also emphasizes on reproducibility of the method. In the present study, the concepts (visual characteristics of Appleton's theory) are well defined. The definition of visual characteristics is provided for the participants (Appendix2). The sampling frame is naturalistic landscapes in urban parks in Kuala Lumpur metropolitan area. The photographs are taken randomly in mentioned frame and the method is reproducible. These conditions validate the method.

To collect images that best fit to naturalistic landscapes, 5 point likert type scale was used. In order to arrive at the image that best described each category (visual characteristic) the participants (experts) were asked to sort images into the defined categories. They were not asked to judge their individual perceived safety for any image. Having enough judges and in odd numbers of them to get reliable results were required. Therefore seven experts were chosen for the second stage and five for the third stage.

Present paper is first step in introducing a procedure for selecting scenes that operationalize Appleton's [16] prospect refuge theory in the context of naturalistic landscapes in urban parks. The procedure can be repeated in other contexts and for operationalizing other theories.

\section{APPENDIX}

\section{Appendix1. Expert panel photo selection (form 1)}

Dear sir/ Madam

Naturalistic landscape is a more natural looking landscape marked by: species diversity, structural complexity of plant communities or absence of uniformity; maximized use of natural elements and usually but not always native plants and animal species; minimized use of artificial elements and overt human control in the design and management; and maximized use of natural or spontaneous processes and ecological principles in the design and management.

Based on the above definition please state that "How much does this scene seem to be naturalistic"?

$1=$ not naturalistic at all, 2=slightly naturalistic, $3=$ moderately naturalistic, $4=$ very much naturalistic, $5=$ extremely naturalistic

\begin{tabular}{|l|l|l|l|l|l|}
\hline $\begin{array}{l}\text { Photo } \\
\text { number }\end{array}$ & 1 & 2 & 3 & 4 & 5 \\
\hline & & & & & \\
\hline & & & & & \\
\hline & & & & & \\
\hline & & & & & \\
\hline & & & & & \\
\hline & & & & & \\
\hline & & & & & \\
\hline
\end{tabular}

\section{Appendix2. Expert panel photo selection (form 2)}

Dear sir/ Madam

I need your help to categorize the photos based on variables of my study. The definitions of variables are as below. Please mark the variable which is suited each photo.

Definition of variables: 
Panorama: Is a wide view from a good vantage- point. Strictly speaking, it implies the ability to see the surrounding landscape through 360 of arc. In practice the word is used quite commonly to denote a broad view.

Vista: The vista is a view which is restricted by conspicuous bounding margins. In a simple vista the general view is obstructed by some intervening screen which contains a limited breach through which the eye can penetrate further.

Secondary Prospect: A hill or other vantage point from which one might expect to have a good view.

Primary Refuge (Concealment): Refers to the view from within a hiding place (the observer is concealed on the setting).

Secondary Refuge (Refuge): Refers to the view of a hiding place from a vantage point outside it (the observer can see hiding places on the setting)

Shadow: Dominant shadows in the setting

Multiple Pathways: To provide the opportunity to have unpredictable or changeable rout to escape.

Movement Ease: Being easy to move through a setting. Meaning that the locomotion is not prevented.

Proximity of Occupied Buildings: To be close to buildings or structures that people who may help are around.

\section{Category sheet}

Please write the number of photo which is matched each category.

\begin{tabular}{|c|c|c|c|c|c|c|c|c|}
\hline $\mathrm{P}$ & $\mathrm{V}$ & $\mathrm{SP}$ & $\mathrm{PR}$ & $\mathrm{SR}$ & $\mathrm{S}$ & $\mathrm{MP}$ & $\mathrm{ME}$ & $\mathrm{POB}$ \\
\hline & & & & & & & & \\
\hline & & & & & & & & \\
\hline & & & & & & & & \\
\hline & & & & & & & & \\
\hline & & & & & & & & \\
\hline & & & & & & & & \\
\hline & & & & & & & & \\
\hline & & & & & & & & \\
\hline
\end{tabular}

$\mathrm{P}=$ Panorama, $\mathrm{V}=\mathrm{Vista}, \quad \mathrm{SP}=$ Secondary Prospect, $\mathrm{PR}=$ Primary Refuge, SR=Secondary Refuge, S=Shadow, MP=Multiple Pathways, ME=Movement Ease, $\mathrm{POB}=$ Proximity of Occupied Buildings

Appendix3. Result summary sheet (for assessing photos in terms of being naturalistic)

$1=$ not at all, 2=slightly, $3=$ moderately, 4=very much, $5=$ extremely

\begin{tabular}{|c|c|c|c|c|c|c|c|c|c|}
\hline \multirow{2}{*}{$\begin{array}{l}\text { Photo } \\
\text { number }\end{array}$} & \multicolumn{7}{|c|}{ Expert number } & \multirow{2}{*}{$\begin{array}{l}\text { Sum of } \\
\text { values }\end{array}$} & \multirow{2}{*}{$\begin{array}{l}\text { Mean of } \\
\text { values }\end{array}$} \\
\hline & 1 & 2 & 3 & 4 & 5 & 6 & 7 & & \\
\hline & & & & & & & & & \\
\hline & & & & & & & & & \\
\hline & & & & & & & & & \\
\hline & & & & & & & & & \\
\hline & & & & & & & & & \\
\hline & & & & & & & & & \\
\hline & & & & & & & & & \\
\hline & & & & & & & & & \\
\hline
\end{tabular}

Appendix4. Result summary sheet (for category)

\begin{tabular}{|l|l|l|l|l|l|l|l|l|l|}
\hline \multicolumn{2}{l}{ P N } & \multicolumn{7}{|c|}{ Frequency selected for } \\
\cline { 2 - 10 } & P & V & S P & P R & S R & S & M P & M E & POB \\
\hline & & & & & & & & & \\
\hline & & & & & & & & & \\
\hline & & & & & & & & & \\
\hline & & & & & & & & & \\
\hline & & & & & & & & & \\
\hline & & & & & & & & & \\
\hline & & & & & & & & & \\
\hline & & & & & & & & & \\
\hline & & & & & & & & & \\
\hline & & & & & & & & & \\
\hline
\end{tabular}

$\mathrm{PN}=$ Photo $\quad$ Number, $\quad \mathrm{P}=$ Panorama, $\quad \mathrm{V}=\mathrm{V}$ ista, $\mathrm{SP}=$ Secondary Prospect, $\mathrm{PR}=$ Primary Refuge, $\mathrm{SR}=$ Secondary Refuge, $\mathrm{S}=$ Shadow, $\mathrm{MP}=$ Multiple Pathways, $\mathrm{ME}=$ Movement Ease, $\mathrm{POB}=$ Proximity of Occupied Buildings

\section{Appendix5. Expert panel photo selection (form 3)}

Dear sir/ Madam

Based on the following definition please state that "how much does this scene represent the variable....."

$1=$ Not at all, 2=Slightly, 3=Moderately, 4=Very much, $5=$ Extremely

Definition of variables:

Panorama: Is a wide view from a good vantage- point. Strictly speaking, it implies the ability to see the surrounding landscape through 360 of arc. In practice the word is used quite commonly to denote a broad view.

Vista: The vista is a view which is restricted by conspicuous bounding margins. In a simple vista the general view is obstructed by some intervening screen which contains a limited breach through which the eye can penetrate further.

Secondary Prospect: A hill or other vantage point from which one might expect to have a good view.

Primary Refuge (Concealment): Refers to the view from within a hiding place (the observer is concealed on the setting).

Secondary Refuge (Refuge): Refers to the view of a hiding place from a vantage point outside it (the observer can see hiding places on the setting)

Shadow: Dominant shadows in the setting

Multiple Pathways: To provide the opportunity to have unpredictable or changeable rout to escape.

Movement Ease: Being easy to move through a setting. Meaning that the locomotion is not prevented.

Proximity of Occupied Buildings: To be close to buildings or structures that people who may help are around.

\begin{tabular}{|l|r|r|r|r|r|}
\hline Panorama & 5 \\
\hline Photo Number & 1 & 2 & 3 & 4 & 5 \\
\hline & & & & & \\
\hline & & & & & \\
\hline & & & & & \\
\hline & & & & & \\
\hline & & & & & \\
\hline & & & & & \\
\hline
\end{tabular}

There were nine tables (one table for one defined variable) which all of them are not presented here. 


\section{Appendix6. Result summary sheet (for final selection)}

This appendix included nine tables the same as next table. Each of them was special for one variable.

Panorama

\begin{tabular}{|l|l|l|l|l|l|l|}
\hline \multirow{2}{*}{$\begin{array}{l}\text { Photo } \\
\text { Number }\end{array}$} & \multicolumn{4}{|c|}{ Expert Number } & \multicolumn{2}{l}{ Sum of the } \\
& values \\
\hline & 1 & 2 & 3 & 4 & 5 & \\
\hline & & & & & & \\
\hline & & & & & & \\
\hline & & & & & & \\
\hline & & & & & & \\
\hline & & & & & & \\
\hline
\end{tabular}

\section{REFERENCES}

[1] P. R. Ehrlich and A. H. Ehrlich, "The value of biodiversity," Ambio Stockholm, vol. 21, issue 3, pp. 219-226, 1992.

[2] S. Gairola and M. Noresah, "Emerging trend of urban green space research and the implications for safeguarding biodiversity: a viewpoint," Nature and science, vol. 8, issue 7, pp. 43-49, 2010.

[3] C. Jim and W. Y. Chen, "Perception and attitude of residents toward urban green spaces in Guangzhou (China)," Environmental Management, vol. 38, issue 3, pp. 338-349, 2006.

[4] P. H. Gobster and L. M. Westphal, "The human dimensions of urban greenways: planning for recreation and related experiences," Landscape and Urban Planning, vol. 68, issue 2, pp. 147-165, 2004.

[5] H. O" zgu"ner, A. Kendle, and R. Bisgrove, "Attitudes of landscape professionals towards naturalistic versus formal urban landscapes in the UK," Landscape and Urban Planning, vol. 81, issue 1, pp. 34-45. 2007.

[6] A. Jorgensen, J. Hitchmough, and N. Dunnett, "Woodland as a setting for housing-appreciation and fear and the contribution to residential satisfaction and place identity in Warrington New Town, UK," Landscape and Urban Planning, vol. 79, issue 3, pp. 273-287, 2007.

[7] J. Burgess, "Focusing on fear: the use of focus groups in a project for the Community Forest Unit, Countryside Commission," Area, vol. 28 , issue 2, pp. 130-135, 1996.

[8] J. Burgess, C. M. Harrison, and M. Limb, "People, parks and the urban green: a study of popular meanings and values for open spaces in the city," Urban Studies, vol. 25, issue 6, pp. 455-473, 1988.

[9] R. Coles and S. Bussey, "Urban forest landscapes in the UKprogressing the social agenda," Landscape and Urban Planning, vol. 52, issue 2, pp. 181-188, 2000.

[10] P. Macnaghten and J. Urry, "Bodies in the woods," Body and Society, vol. 6, issue 3-4, pp. 166-182, 2000.

[11] A. Forsyth, People and Urban Green Areas: Perception and Use, University of Minnesota, Design Center for American Urban Landscapes, 2003.

[12] R. Parsons, "Conflict between ecological sustainability and environmental aesthetics: Conundrum, canard or curiosity," Landscape and Urban Planning, vol. 32, issue 3, pp. 227-244, 1995.

[13] R. S. Ulrich, "Human responses to vegetation and landscapes," Landscape and Urban Planning, vol. 13, pp. 29-44, 1986.

[14] H. W. Schroeder, "Environment, behaviour and design research on urban forests," in Advances in Environment, Behaviour and Design, E.
H. Zube and G. T. Moore eds., New York: Plenum Publishing Corporation, vol. 2, 1989.

[15] L. Anderson and G. Stokes, "Planting in parking lots to improve perceived attractiveness and security," Journal of Arboriculture, vol. 15 , issue 1, pp. 7-10, 1989 .

[16] J. Appleton, The Experience of Landscape, New York: John Wiley and Sons, 1975, pp. 70-90.

[17] J. Appleton, "Prospects and refuges re-visited," Landscape Journal, vol. 3, issue 2, pp. 91-103, 1984.

[18] D. T. Luymes and K. Tamminga, "Integrating public safety and use into planning urban greenways," Landscape and Urban Planning, vol. 33, issue 1, pp. 391-400, 1995 .

[19] L. J. Loewen, G. D. Steel, and P. Suedfeld, "Perceived safety from crime in the urban environment," Journal of Environmental Psychology, vol. 13, no. 4, pp. 323-331, 1993.

[20] D. Chapin, "Making green places safer places: experiences in New York City," Landscape Architecture Review, vol. 12, issue 3, pp. 16-18, 1991.

[21] B. Fisher and J. Nasar, "Prospect and refuge: fear of crime and the building design characteristics," Paper presented at the joint ASCP and ASEOP international conference, Oxford, England, July 11, 1991.

[22] J. Hassinger, "Fear of crime in public environments," Journal of Architectural and Planning Research, vol. 2, pp. 289-300, 1985

[23] O. Newman, Crime Prevention Through Architectural Design, Washington, DC: US Department of Justice, Law Enforcement Assistance Administration, 1971.

[24] N. L. Kirk, Factors Affecting Perceptions of Safety in a Campus Environment, EDRA: Environmental Design Research Association, 1988.

[25] D. M. Woodcock, A Functionalist Approach to Environmental Preference (Unpublished Doctoral Dissertation), University of Michigan, 1982

[26] T. R. Herzog and G. E. Kutzli, "Preference and perceived danger in field/forest settings," Environment and Behavior, vol. 34, issue 6, pp. 819-835, 2002.

[27] T. R. Herzog and L. S. Kropscott, "Legibility, mystery, and visual access as predictors of preference and perceived danger in forest settings without pathways," Environment and Behavior, vol. 36, issue 5, pp. 659-677, 2004.

[28] A. E. Stamps, "Mystery, complexity, legibility and coherence: a meta-analysis," Journal of Environmental Psychology, vol. 24, issue 1, pp. 1-16, 2004.

Sara Farbod was born in Mashhad, Iran in 1978. She earned a master degree in architecture from Iran University of Science and Technology, Tehran, Iran, in 2003. In 2013 she finished her Ph.D. in landscape studies in University Putra Malaysia, Malaysia.

She has been working as a lecturer at the Department of Architecture in Azad University, Neyshabour Branch, Iran, since 2003. Simultaneously, Sara worked as an architect in her office as a consultant for private and governmental projects. Her publications include "Perception of Safety in Naturalistic Urban Parks, in sustain 2011," Proceeding of The Second International Conference on Sustainable Future for Human Security, Kyoto University, Kyoto, Japan, October 8-9, and "Safety Perception and Concerns in Naturalistic Landscapes in Urban Parks in Malaysia," Security Journal, (ISI journal; ISSN 0955-1662 ).

Dr. Sara Farbod is a member of Iran Construction Engineering Organization. She has reviewed some papers for Security Journal. 